・编者按・

\title{
世界自然保护大会与世界自然保护联盟
}

\author{
马克平 ${ }^{*}$
}

(中国科学院植物研究所植被与环境变化国家重点实验室, 北京 100093)

\section{World Conservation Congress and International Union for the Conservation of Nature}

\author{
Keping $\mathrm{Ma}^{*}$ \\ State Key Laboratory of Vegetation and Environmental Change, Institute of Botany, Chinese Academy of Sciences, Beijing 100093
}

第六届世界自然保护大会将于2016年9月1-10 日在美国夏威夷召开, 主题是“处于十字路口的地 球: 决定可持续的未来之路”。大会包括两个部分： (1)自然保护论坛; (2)世界自然保护联盟(IUCN)会 员大会和相关活动。自然保护论坛主要包括7种类 型的活动, 即高级别论坛(high level session)、研讨 会(workshop)、圆桌讨论(knowledge café)、壁报 (poster)、培训班 (conservation campus)、专题馆 (pavilion)和社交活动(social event)。目前已经确定的 活动达 1,298 个 (https://portals.iucn.org/congress/sessions)。此外, 还有大型展览馆提供各种展位。内容 非常丰富, 绝对是自然保护领域难得一遇的盛会。 高级别论坛几乎场场精彩, 其他活动则要根据自己 的兴趣做出选择。另外一部分是IUCN团体会员的 活动, 决定未来4年(2017-2020)联盟的走向和核心 管理机构。主要内容有: (1)审议通过联盟总干事工 作报告和 6 个委员会主席的工作报告; (2)对提案表 决, 超过半数会员赞成的提案变成大会决议 (resolution)或建议(recommendation); (3)审议通过新 时期工作方案(programme of work); (4)区域会员委 员会会议, 主要是听取候选人的竞选演讲, 讨论区 域重点工作; (5)选举新一届的理事会(包括理事和 理事长)以及 6 个专业委员会的主席。

IUCN于1948年在法国枫丹白露(Fontainebleau) 成立, 为全球规模最大、历史最长、唯一在联合国 大会具有常任观察员席位的自然保护组织。目前有 1,283 个团体会员, 其中国家和政府机构会员 217 个; 专门委员会会员 16,151 人; 会员来自 161 个国家; 秘
书处超过 1,000 人(www.iucn.org/)。四年一次的全体 会员大会是联盟的最高管理机构, 大会期间的管理 由理事会领导。理事会指导秘书处、专门委员会和 团体会员的工作。IUCN的愿景是“一个珍视和保护 自然的公平世界”(a just world that values and conserves nature), 其使命是“发动社会各界共同保护自 然的完整性和多样性, 并使人们公平且可持续地利 用自然”(www.iucn.org/)。物种受威胁程度评估标 准、现状报告、红色名录, 生态系统红色名录, 自 然保护地分类和管理指南, 自然保护地绿色名录, 世界自然保护地数据库等是IUCN的标志性成果。

IUCN 是自然保护领域思想和行动的引领者, 由其为主起草的《世界自然保护纲要》(World Conservation Strategy)于1980年在35个国家同时发 布, 第一次提出“可持续发展”的概念; 此后, 又陆 续发布两个重要文件: 《保护地球》(Caring for the Earth, 1991)和《全球生物多样性战略》(Global Biodiversity Strategy, 1992)。这3个文件被认为是对 当代自然保护理念、战略和行动影响最大的文件 (https://en.wikipedia.org/wiki/)。IUCN还是自然保护 国际规则的重要推动者和起草者, 如大家熟知的 《生物多样性公约》(Convention on Biological Diversity, CBD)、《濒危野生动植物物种国际贸易公 约》(the Convention on International Trade in Endangered Species of Wild Fauna and Flora, CITES)、 《世界遗产公约》(the World Heritage Convention)、 《湿地公约》(the Ramsar Convention on Wetlands) 等。IUCN通过世界自然保护大会的决议和建议以

* 通讯作者 Author for correspondence. E-mail: kpma@ibcas.ac.cn 
及四年期工作方案和重点方向(theme)指导自己和 全球自然保护领域的工作。

IUCN是全球自然保护领域的领导者, 其作用 至关重要。本人在2007-2012年间任IUCN理事会成 员，去年 8 月开始为期 4 年的亚洲区域会员委员会主 席的任职, 应该说对IUCN有一定的了解。现将几点 认识发表于此, 就教于同行。

\section{1 重提案轻落实}

现在正值世界自然保护大会前夕，会员们可以 在线对提案发表评论并投票。但IUCN重视提案的 审议和投票过程, 而对于大会决议的执行重视不 够。提案者往往满足于提案被大会通过变成决议, 很少有人继续努力落实提案的内容, 并把提案一决 议一实践很好地结合起来。理论上说, 形成的决议 由秘书处组织实施, 但由于提案太多, 大部分提案 变成决议或建议后处于无人负责的状态。只有少数 提案真正在大会之后的联盟行动中得到落实。决议 相关的进展也缺乏系统全面的总结, 从IUCN官网 很容易发现这个问题。

\section{2 重眼前轻长远}

IUCN与某些会员如世界自然基金会(WWF)和 大自然保护协会 $(\mathrm{TNC})$ 等相比, 财务状况一直不理 想。秘书处主要精力花在争取项目上, 但没有花费 充分的精力致力于可能给联盟带来长远利益的战 略性工作上。IUCN近年来没有较大影响力的成果 产出就与此相关。而且, 所执行的项目与相关的自 然保护组织趋同。标志性工作缺乏, 其影响力明显 减弱。建议加强有特色的工作, 强调基于自然的解 决方案和基于科学的保护行动等理念。以专门委员 会为主推动的基于科学基础的保护工具为 IUCN赢 得了很大荣誉和影响力, 应大力发展。在引领全球 自然保护思想和行动规则方面还应该开展更多的 战略研究, 并处理好近期目标和长远影响的关系。

\section{3 重行动轻指导}

联盟的 3 个组成部分中，秘书处由全时工作人 员组成, 是联盟工作的主力; 专门委员会在主席的 领导下工作进展也不错; 团体会员的作用则发挥得 不够理想。理论上说，团体会员是联盟的核心部分， 因为联盟的理事会、四年期工作方案以及大会决议 和建议都是由团体会员投票决定的。然而，大会结
束之后，基本上看不到会员对联盟发展的作用。团 体会员的作用被严重忽视了。事实上，大多数会员 在两次大会期间一直在大会决议和工作方案的指 导下为自然保护努力工作，但没有及时充分地反映 到联盟的工作进展中。主要原因是大多数成员习惯 性地认为只有秘书处和专门委员会牵头完成的工 作才隶属于IUCN，而团体会员按照联盟确定的方 向自行完成的工作不好纳入IUCN的框架。联盟对 全球自然保护工作不仅负有自己努力工作的责任， 还有对联盟内所有成员和联盟外的相关工作予以 指导的责任。后者应该得到足够的重视，并采取积 极有效的措施予以推动。

\section{4 重自身发展轻沟通合作}

IUCN是最复杂的自然保护体系, 三个主要组 成部分之间的合作需要大大加强。首先, 组成部分 之间的沟通不理想, 工作上经常出现不能及时互通 信息的情况; 其次，团体会员和专门委员会会员经 常感到参与秘书处组织的项目的机会和程度不够; 秘书处内部总部与区域以及国家办公室之间工作 不协调的事情时有发生。有鉴于此, 2011年联盟理 事会第76次会议和2012年世界自然保护大会通过 了关于“联盟是同一个项目”(IUCN's One Programme)的决议(第19号决议), 号召IUCN的政府会 员和非政府会员、理事会、国家和区域会员委员会、 专门委员会成员和秘书处携手并肩，共同制订和执 行工作方案。经过各个方面的共同努力, 情况有所 改善, 但对比决议的要求仍有明显差距。

\section{5 重运营模式沿用轻运营模式改革}

目前IUCN的运营模式存在诸多弊端，如内部 资源竞争、经费分配不合理、缺乏激励机制、几无 专门的经费筹集团队等问题。联盟的财务状况一直 不佳, 与运营模式不合理有直接关系。三个主要组 成部分都在为 IUCN的发展而努力, 但经费基本上 都花在秘书处日常运行上，专门委员会和团体会员 的工作经费都要靠自己筹集。秘书处内部，总部、 区域办公室和国家办公室之间的关系也不协调, 亟 待改进。健康而富于活力的运营模式是联盟存在与 发展的保证。IUCN运营模式改革势在必行。

致谢: 感谢IUCN秘书处朱春全和Admund Farrow博士 的建议。 